\title{
DAS GREVES DO ABC AO CONSELHO DE RELAÇÕES DE TRABALHO: CHANCES E LIMITES DA AÇÃO SINDICAL INSTITUCIONAL
}

Roberto Véras de Oliveira ${ }^{a}$

aé professor do Programa de Pós-Graduação em Sociologia da Universidade Federal da Paraíba

(UFPB). João Pessoa, PB, Brasil.E-mail: <roberto.veras.2002@gmail.com>

Orcid: 0000-0001-7751-6863

Mario Henrique Guedes Ladosky

'é professor do Programa de Pós-Graduação em Ciências Sociais da Universidade Federal de Campina Grande (UFCG). Campina Grande,PB, Brasil. E-mail: <mhladosky@gmail.com>

Orcid: 0000-0002-6423-1196

http://dx.doi.org/10.1590/0102-097131/104

\section{Introdução}

Este artigo tem como propósito reconstituir os nexos entre o sindicalismo oriundo das greves operárias e populares desencadeadas a partir de fins da década de 1970 e as condições recentes de regulação do trabalho no Brasil, com particular foco na atuação sindical no Conselho de Relações de Trabalho (CRT), criado em 2010. Não se trata de realizar aqui um balanço dos últimos 40 anos, seja da trajetória do sindicalismo brasileiro, seja dos caminhos da regulação do trabalho no país. Tão somente percorremos em grandes linhas a trajetória sindical desde então, até nos determos no CRT, em sua formatação e agenda, para assim analisar as chances e os limites propiciados à atuação sindical. Para tanto, dialogamos com a bibliografia referida ao tema e com pesquisas e reflexões acumuladas pelos autores, assim como apoiamo-nos em pesquisa documental (atas do CRT, leis, decretos, medidas provisórias e portarias), e midiática, além de entrevistas com membros das bancadas sindical e governista do CRT.

A explosão de greves e manifestações de trabalhadores urbanos e rurais, da indústria e dos serviços, sindicais 
e populares, que se fizeram presentes em todo o território nacional, e que tiveram como principal referência as greves operárias na região do ABC Paulista de 1978 a 1980, está agora completando quatro décadas de lutas por democracia e direitos sociais no Brasil.

A combinação de crise econômica, esgotamento político do regime militar e anseio pelo retorno da democracia produziram o contexto das lutas sindicais e populares que se estenderam do final dos anos 1970 aos anos 1980. Surgiram diversas interpretações nos estudos basilares que então se produziram: a da revolta frente ao arrocho salarial (Humphrey, 1982), a da busca pela dignidade (Abramo, 1999), a da luta por cidadania (Rodrigues, 2011), a da recusa como estratégia central (Maroni, 1982), a da luta contra a superexploração capitalista (Antunes, 1988), a da importância histórica da entrada em cena de "novos personagens" (Sader, 1988), entre outras.

No campo sindical, a bandeira da liberdade e autonomia sindical se associou à luta pela redemocratização do país. Um novo sindicalismo emergiu desse contexto, dando ensejo à criação da Central Única dos Trabalhadores (CUT) em 1983, que veio a desempenhar papel de destaque no debate sobre democracia e cidadania no Brasil nos anos que se seguiram (Oliveira, 2011).

Outros projetos sindicais também surgiram nesse momento. Ainda em 1983 constituiu-se, com um perfil político mais moderado e uma posição de defesa do sistema confederativo, a Coordenação Nacional das Classes Trabalhadoras (Conclat), convertida em Central Geral dos Trabalhadores em 1986, e em Confederação Geral dos Trabalhadores (CGT) em 1988. Em 1989 a CGT-Central foi recriada a partir de uma divisão na CGT-Confederação, passando a existir por alguns anos duas CGTs. Desta última saiu um grupo que criou a Força Sindical (FS), com um perfil 
pragmático, em defesa de um "sindicalismo de resultados" (Rodrigues e Cardoso, 1993).

Assim armado, o sindicalismo enfrentará uma agenda que, nos anos 1980, terá como marcos o processo constituinte, a partir de 1986, e a promulgação de uma nova Constituição, em 1988.

\section{Entre a ação direta e a ação institucional}

O novo sindicalismo surge no embate direto, nas greves e mobilizações de rua, contra empresários e governos, contudo conquistando, por meio da estruturação de suas formas de organização e representação e do avanço das liberdades políticas e sindicais, crescente reconhecimento institucional.

$\mathrm{Na}$ instalação da Assembleia Constituinte, mesmo prevalecendo a posição conservadora (que tomou como base o Congresso Nacional, e não uma "Constituinte Livre e Soberana"), o sindicalismo identificado com a CUT e a maioria dos movimentos populares decidiram dela participar. Tal decisão não se fez, contudo, sem acalorados e tensos debates internos (Ladosky, 2009; Oliveira, 2011).

A Constituição promulgada em 1988 contemplou elementos de regulação pública do mercado (balizando-se pelas referências da "soberania nacional", da "empresa nacional", da limitação da taxa de juro, da "função social" da propriedade, da defesa do consumidor e do meio ambiente, entre outras). Foram previstos instrumentos de participação da população nas tomadas de decisões da sociedade (com o "plebiscito", o "referendo" e a "iniciativa popular", além da garantia do direito de greve, da livre associação e do alargamento do direito de voto). Houve uma ampliação das funções do Estado como provedor de serviços de saúde, educação, previdência e assistência social, habitação, saneamento básico etc. A ideia de direitos 
sociais em uma perspectiva universalista se fez central no texto constitucional (Telles, 1999).

Quanto ao tema da regulação laboral, constitucionalizaram-se direitos previstos na Consolidação das Leis do Trabalho, a CLT (licença maternidade e paternidade, férias e 1/3 de férias, $13^{\circ}$ salário, Fundo de Garantia do Tempo de Serviço [FGTS], seguro desemprego etc.), além de serem reconhecidos os direitos de greve e de sindicalização para os servidores públicos e de representação dos trabalhadores nas empresas com mais de duzentos empregados, assim como foram eliminados os mecanismos de intervenção governamental nos sindicatos, prevendo-se maior liberdade de organização, de negociação coletiva e de eleições sindicais. A isso se associou a constituição de um sistema de seguridade social de caráter universal, incluindo o Sistema Único de Saúde (SUS), o sistema de Previdência Social e a Assistência Social.

Alguns dos direitos aprovados ficaram, entretanto, na dependência de regulamentação específica posterior, como os direitos de greve (especialmente para os servidores púbicos) e de organização no local de trabalho. No capítulo sindical, embora tenha promovido a liberalização dos aspectos mais restritivos da estrutura corporativista sobre os sindicatos, a Constituição de 1988 também tornou constitucionais elementos da estrutura sindical, a exemplo do monopólio da representação, da contribuição sindical obrigatória e do poder normativo da Justiça do Trabalho, configurando assim um modelo híbrido de regulação sindical (Boito Júnior, 1991).

Quando de sua promulgação, a nova Carta foi alvo de críticas por conta de suas insuficiências, ao preservar estruturas tradicionais de poder e privilégios, além de não ter colocado em xeque o caráter estruturalmente desigual da sociedade brasileira. Essa posição se inverteu quando, desde início dos anos 1990, vieram os ataques aos capítulos sociais pelas forças de inspiração neoliberal e conservadora. 


\section{Maior participação sindical institucional como compensação?}

Com a eleição presidencial de Fernando Collor em 1990, impôs-se uma agenda de liberalização da economia, privatizações, reforma administrativa (gerencialista) do Estado e estímulo à reestruturação produtiva que levaram ao desemprego e à flexibilização, informalização e precarização do trabalho (Pochmann, 2009).

Esse quadro produziu um efeito de desmobilização dos trabalhadores e de adoção de uma estratégia sindical defensiva (Oliveira, 2011). O surgimento da FS, em 1991, em franca concorrência com a CUT, sinalizava que a disputa ideológica na sociedade refletia no campo sindical. A defesa de um "sindicalismo de resultados" e um de seus principais expoentes, Antônio Rogério Magri, para o Ministério do Trabalho, revelavam o perfil da nova central sindical.

Com o impeachment de Collor em 1992, assumiu Itamar Franco, que promoveu uma perspectiva negocial de condução da agenda do trabalho no país. Conforme Oliveira (2002), a partir de uma rodada nacional de debates patrocinada pelo Ministério do Trabalho, em 1993, explicitaram-se três posições principais.

Colocaram-se em defesa de uma reforma global do sistema de relações de trabalho a CUT, a FS e o Pensamento Nacional das Bases Empresariais (PNBE). Inspirando-se nas orientações da OIT, voltaram-se para a democratização das relações de trabalho, com liberdade e autonomia sindical, uma legislação de sustento à organização sindical e à negociação coletiva e a adoção de um novo código do trabalho. Para isso, estes grupos defendiam a eliminação da unicidade sindical, do imposto sindical e do poder normativo da Justiça do Trabalho. Mas a crescente hegemonia do discurso neoliberal na sociedade, as fragilidades da liderança empresarial do PNBE e a posição da FS em favor das medidas de flexibilização das relações de trabalho, juntas enfraqueceram tal perspectiva. 
Convergiram em favor da desregulamentação das relações de trabalho as principais organizações empresariais, a exemplo da Federação da Indústria do Estado de São Paulo (Fiesp), da Confederação Nacional da Indústria (CNI), da Confederação Nacional da Agricultura (CNA) e da Federação Nacional dos Bancos (Febraban). Mirava-se na defesa das "livres negociações" por empresa, sem legislação de sustento, e na prevalência do negociado sobre o legislado. Ao mesmo tempo, apoiavam em geral a manutenção da unicidade sindical, do sistema confederativo e do poder normativo da Justiça do Trabalho.

Um terceiro grupo se firmou na defesa de uma reforma parcial das relações de trabalho, reunindo os segmentos identificados com o sistema confederativo, entre os quais a CGTCentral, a CGT-Confederação, a Confederação Nacional dos Trabalhadores Industriais (CNTI), a Confederação Nacional dos Trabalhadores no Comércio (CNTC) e a Confederação 102 Nacional dos Trabalhadores da Agricultura (Contag). Estas confederações defendiam sobretudo a unicidade sindical, as contribuições obrigatórias, o poder normativo da Justiça do Trabalho, os juízes classistas, o sistema confederativo e a CLT.

Nos governos Collor e, principalmente, Itamar, foram criados vários fóruns consultivos referidos às políticas industriais, no contexto da reestruturação produtiva, nos quais as organizações sindicais buscaram se fazer representar. O mais expressivo deles foi o caso das Câmaras Setoriais. Estas foram constituídas entre 1992 e 1993 como espaços de negociação envolvendo governo, empresários e sindicatos, em várias áreas da economia (metalúrgica, máquinas agrícolas, química, construção civil), e se destacaram nesse momento. Os dois acordos da Câmara Setorial do Setor Automobilístico se converteram em sua principal referência, resultando da iniciativa do Sindicato dos Metalúrgicos do ABC, embora tenham gerado fortes controvérsias no interior da CUT. Para Arbix (1996), tal experiência teve o mérito de 
relativizar uma postura sindical de confronto com empresários e Estado e uma prática de exclusão dos trabalhadores nas decisões sobre políticas públicas. Para Oliveira (1998), o que estava em questão era a oportunidade de construção, no Brasil, de um embrião de esfera pública, que teria como pressuposto a publicização dos interesses privados em disputa na sociedade. Essa experiência influenciou a posição da CUT sobre a regulação das relações de trabalho ${ }^{1}$. O capítulo das Câmaras Setoriais foi, no entanto, encerrado por decisão do então Ministro da Fazenda, Fernando Henrique Cardoso.

As práticas de negociação, que antes praticamente se restringiam às campanhas salariais anuais, se expandiram com as crescentes formas de participação sindical institucional, sobretudo pelos novos espaços abertos pela nova Constituição, mas também como compensação pela retração da capacidade de mobilização sindical.

O governo seguinte, de Fernando Henrique Cardoso, fez uma clara opção pela suspensão do diálogo institucional (esboçado no governo Itamar) em favor da desregulamentação dos direitos laborais (contrariando o espírito da Constituição de 1988), contando para isso com um forte suporte midiático. Contudo, o governo FHC decidiu por alterações pontuais, embora sistemáticas, da legislação trabalhista (preferencialmente por meio de Medidas Provisórias), visando com isso diminuir as resistências. Os que se opunham à desregulamentação, defensores das reformas global ou parcial do sistema de relações de trabalho, foram postos na defensiva.

Ao final deste período, as mudanças promovidas concorreram para a flexibilização das relações de trabalho, com perdas de direitos, incluindo a instituição do trabalho por tempo determinado, o trabalho voluntário, sem encargos sociais e

\footnotetext{
1 Resultou daí o projeto da CUT de Sistema Democrático de Relações de Trabalho, visando disputar com as forças neoliberais o sentido de "modernização das relações de trabalho" (Central Única dos Trabalhadores, 1995).
} 
trabalhistas, o "banco de horas", o trabalho por tempo parcial, a suspensão do contrato de trabalho, o rito sumaríssimo, o fim do princípio da ultratividade em acordos e convenções coletivas, o fim da estabilidade do servidor público, a substituição do critério de aposentadoria por tempo de serviço pelo de tempo de contribuição, entre outras (Krein, 2007).

Em 2001, o governo tentou alterar o artigo $7^{\circ} \mathrm{da}$ Constituição Federal, propondo a primazia do negociado sobre o legislado. Mas, diante das resistências, voltou-se para o artigo 618 da CLT, cuja modificação como lei ordinária exigia um quórum mais baixo. $\mathrm{O}$ governo encaminhou, em regime de urgência, o Projeto de Lei nº 5.483 ao Congresso Nacional. Apesar de aprovado na Câmara, não houve tempo de submeter o projeto ao Senado. Em 2003, o novo governo o retirou de pauta.

Ao longo dos anos 1990, forjou-se uma nova geração de trabalhadores, com parcelas expressivas expostas a uma crise 104 generalizada de emprego e a formas mais flexíveis, informais e precárias de trabalho (Pochmann, 1999). Pode-se supor, neste contexto, uma subjetividade em que, para estes trabalhadores e trabalhadoras, o neoliberalismo não era uma ameaça, mas um fato irremediável.

O sindicalismo da CUT, ao perder capacidade de mobilização e de comunicação com as novas gerações de trabalhadores, assumiu uma posição mais defensiva no campo da luta direta, e ao mesmo tempo buscou compensá-la com uma postura mais propositiva no plano da ação institucional e da negociação social (visando influenciar na formulação, na fiscalização e no acompanhamento de políticas sociais). Quanto à FS, mesmo sem cargo no governo, deu importante apoio à agenda de reformas e de privatizações (Trópia, 2009).

Muitos dos espaços de gestão compartilhada na forma de conselhos, comissões, fóruns, na saúde, educação, emprego, criança e adolescente, desenvolvimento rural etc. serviram a propósitos de cooptação/adesão dos setores que atuavam 
na luta por direitos de cidadania (Tatagiba, 2002). Isso envolveu de modo especial o sindicalismo. Lembra Comin (1995) que, com a incorporação no texto constitucional e a participação de representantes dos trabalhadores e de empregadores em órgãos públicos de gestão de fundos previdenciários, com destaque para o FGTS, a CUT de pronto buscou ocupar nesses espaços de gestão um assento e, junto com as demais centrais sindicais, passou a reivindicar espaço também em outros organismos tripartites de natureza similar, como o Conselho Deliberativo do Fundo de Amparo ao Trabalhador (Codefat), o Fundo de Desenvolvimento Social (FDS) e Conselhos Nacionais da Previdência, da Seguridade Social, da Saúde, da Educação, do Menor e do Adolescente, e da Assistência Social.

A representação sindical no sistema Codefat adquiriu importância. O FAT e o Codefat foram criados em 1990 pela Lei $\mathrm{n}^{\circ}$ 7.998. Além de uma composição tripartite e paritária, o Conselho foi instituído com caráter deliberativo. A partir de 1994 passaram a ser constituídas as comissões/conselhos tripartites estaduais e municipais de emprego/trabalho ${ }^{2}$. O interesse sindical pelo Codefat cresceu com o Plano Nacional de Formação Profissional (Planfor) do Ministério do Trabalho, lançado em 1995. A partir de então, tornava-se possível às entidades sindicais representadas no Codefat disputarem a aprovação de recursos do FAT para financiar projetos próprios de qualificação profissional, nos quais se apresentavam como proponentes e executoras (gerando conflito de interesse com seu papel de fiscais dos recursos do FAT). Com o Planfor e, no governo Lula, com o Plano Nacional de Qualificação (PNQ), a crítica sindical ao caráter compensatório e focal de tais políticas arrefeceu (Oliveira, 2006).

\footnotetext{
2 A diferença básica é que uma comissão pode ser criada por ato administrativo do respectivo poder executivo, enquanto um conselho só pode ser criado por lei, assumindo caráter mais deliberativo.
} 
Nos governos de orientação neoliberal, a participação sindical em espaços institucionais se mostrou um campo restrito e permeado de riscos, votado a lidar fundamentalmente com a gestão de políticas sociais compensatórias e focais. Enquanto isso, as mudanças na regulação do trabalho passaram por decretos e medidas provisórias presidenciais, em uma conexão estreita entre ações governamentais e demandas empresariais.

\section{Uma nova oportunidade com o governo Lula e o Fórum Nacional do Trabalho}

Um novo cenário se configurou com a eleição de Lula. Um programa orientado à defesa do social, da produção, do desenvolvimento e do resgate do projeto nacional sinalizou um contraponto ao neoliberalismo. Contudo, como governo de coalizão, 106 precisou lidar com interesses contraditórios, desde as demandas de movimentos sociais, sindicais e ambientalistas, além de segmentos empresariais em defesa da produção face à financeirização da economia, até as exigências do capital financeiro, do rentismo e dos políticos clientelistas pertencentes à base aliada.

Sobre o período que se inaugurou com a presidência de Lula e que se estendeu até o impeachment de Dilma, em 2016, é certo que não se produziram mudanças estruturais no mercado de trabalho no país. Também não se pode dizer que não houve medidas governamentais de caráter flexibilizador das relações de trabalho. Contudo, apesar das contradições e dos limites que tal período encerrou, são inegáveis as melhoras na situação dos trabalhadores. Ao crescimento econômico se associou o aumento dos níveis de emprego, a crescente formalização e elevação da renda média dos trabalhadores, especialmente com a 
política de valorização do salário-mínimo ${ }^{3}$ (Baltar e Krein, 2013; Krein e Biavaschi, 2015).

A esse contexto se aliou a promoção de espaços de negociação social, a exemplo do Conselho Nacional de Desenvolvimento Econômico e Social (CDES), do Fórum Nacional do Trabalho (FNT), da Mesa Nacional de Negociação Coletiva para servidores federais, do Fórum Nacional da Previdência Social, de inúmeras conferências ministeriais realizadas nas pastas de trabalho e emprego, saúde, educação, meio ambiente, cidades, entre outros. Com isso, ampliaram-se as condições de participação e influência sindical na regulação do trabalho ${ }^{4}$. Entretanto, como veremos, limites decisivos se impuseram.

No CDES prevaleceu uma discussão mais ampla sobre políticas de desenvolvimento e empreendedorismo. A questão do trabalho surgiu pontualmente, muitas vezes por pressão empresarial, por maior flexibilização das relações de trabalho, ou mesmo por proposição governamental. Mas, mesmo não tratando da reforma trabalhista, várias políticas ali inspiradas tiveram implicações para a regulação do trabalho e, de maneiras diversas, produziram um efeito de flexibilização, a exemplo dos programas Super Simples e Microempreendedor Individual (MEI) e das novas regras de indenização trabalhista com a Lei de Falências (Krein e Biavaschi, 2015).

Quanto à CUT, esta atribuiu maior ênfase aos ganhos sociais e laborais trazidos com o bom desempenho da economia do que a medidas reguladoras dos contratos de

\footnotetext{
3 Sob pressão sindical, foi criada uma Comissão Quadripartite - com governo, trabalhadores, empregadores e aposentados - para elaborar uma política permanente de reajuste do salário-mínimo, sendo esta aprovada pelo Congresso em 2008.

${ }^{4}$ No caso particular da CUT, apesar das divergências internas, prevaleceu a disposição de participar propositivamente dos novos espaços, evitando críticas ao governo. Quanto a isso, um dos momentos mais críticos ocorreu por ocasião da Reforma da Previdência, quando um grupo dissidente, identificado com o Partido Socialista dos Trabalhadores Unificado (PSTU), criou em 2004 a Coordenação Nacional de Lutas (Conlutas) (Galvão e Trópia, 2014).
} 
trabalho. A reação sindical se fazia sobretudo quando surgiam ameaças empresariais ou mesmo governamentais aos direitos trabalhistas.

No campo da regulação do trabalho, de imediato, o governo solicitou ao Congresso o arquivamento de dois Projetos de Lei da era FHC, o de n⿳ 5.483, de 2001 (atribuindo prioridade do negociado sobre o legislado), e o de n⿳0 4.302, de 1998 (que liberalizava a utilização da terceirização). Ainda em 2003 foi instituído o Fórum Nacional do Trabalho (FNT) ${ }^{5}$ (Decreto Presidencial no $4.796^{6}$ ), de composição tripartite e paritária, com o fim de se tornar o principal espaço de concertação nacional entre trabalhadores, empresários e governo, visando por essa via atualizar a legislação sindical e trabalhista. Antes de sua instalação, porém, foi realizada em agosto do mesmo ano uma rodada de 27 Conferências Estaduais.

O Fórum previa uma plenária com 72 representantes, sendo 21 de cada uma das três bancadas principais, mais 108 nove de micro e pequenas empresas, cooperativas e outras formas de trabalho, com igual número de suplentes. Previa, ainda, oito grupos temáticos (GTs), sobre: organização sindical; negociação coletiva; sistema de composição de conflitos individuais e coletivos; legislação do trabalho; organização administrativa e judiciária; normas administrativas sobre condições de trabalho; qualificação e certificação profissional; micro e pequenas empresas, autogestão e informalidade.

A Comissão de Sistematização, com 21 membros equitativamente distribuídos entre as bancadas, teria a atribuição de receber as contribuições dos GTs, das Conferências Estaduais e da consultoria técnica, sistematizá-las e encaminhá-las à plenária do Fórum para deliberação final.

\footnotetext{
${ }_{5}^{5}$ Nesse momento também havia sido retomado o debate sobre o Sistema Público de Emprego, com a realização de dois congressos nacionais tripartites, em 2004 e 2005. No entanto, apenas em 2016 o governo apresentou um Projeto de Lei (PL) com esse fim ( $n^{\circ}$ 5278), tendo sido convertido em lei em 2018 ( $\mathrm{n}^{\mathrm{o}}$ 13.667).

${ }^{6}$ Disponível em: <http://bit.ly/2zyAcX0>. Acesso em: 11 jul. 2018.
} 
Em seu discurso na cerimônia de lançamento do Fórum, Lula relacionou-o à trajetória do sindicalismo brasileiro e à dele própria ${ }^{7}$. Enfatizou que o movimento sindical "evoluiu muito", mas que, como uma exigência contemporânea, havia necessidade de "adequação" da legislação trabalhista aos novos tempos. Ao mesmo tempo, o presidente relembrou o passado de lutas do sindicalismo brasileiro, mas destaca a importância na atualidade da "convivência democrática":

A grandiosidade do Fórum é que vai permitir que a convivência democrática de vocês, na diversidade de pensamento que têm sobre as reformas que precisam ser feitas, encontre o caminho do meio. O caminho do meio sempre é o caminho que possibilita construirmos o consenso, construirmos uma maioria e fazermos as mudanças, sem a pressa daqueles que achavam, algum dia, que, para fazer um contrato coletivo de trabalho, era necessário rasgar a CLT, ou aqueles que achavam que era possível fazer um contrato de trabalho mantendo a CLT em toda sua plenitude ${ }^{8}$.

O então presidente indicou que alguns direitos deveriam ser mantidos, mas outros reformulados, e que as empresas, conforme seu tamanho, deveriam ter tratamento diferenciado quanto a isso. Acenou para o sindicalismo com o atendimento de seu pleito: "nós temos várias centrais sindicais, nenhuma reconhecida por lei. Nenhuma. Entretanto, elas funcionam como se fossem reconhecidas, quando seria muito mais fácil estabelecer logo a normatização e dar legalidade às entidades”. Mas também lhe endereça uma crítica e um chamado à responsabilidade com o novo momento...

7 Disponível em: <http://bit.ly/2u9MLTa>. Acesso em: 11 jul. 2018.

8 Disponível em: <http://bit.ly/2u9MLTa>. Acesso em: 11 jul. 2018. 
Eu estou convencido de que o movimento sindical brasileiro tem que dar um salto de qualidade e extrapolar os limites do corporativismo [...]. Muitas vezes, a nossa cultura sindical permitiu que a gente só fosse economicista. "Então, acabou a data-base, acabou a nossa obrigação, vamos esperar o ano que vem para ver o que vai acontecer" [...]. Eu digo sempre para os meus amigos sindicalistas assim: o tempo de ser sindicato apenas de contestação já passou, e eu, possivelmente, tenha me notabilizado por isso. Agora, a História está a exigir tanto dos trabalhadores como dos empresários uma outra cabeça. Uma outra forma de comportamento. Ou seja, a solução dos problemas da sociedade brasileira passa pelo fato de vocês se entenderem. Para discutir, desde a geração de postos de trabalho a direitos, que têm que ser mantidos. Outros têm que ser reformulados. Há tratamentos diferenciados entre empresas, em função dos seus tamanhos ${ }^{9}$.

Para alguns mais críticos, o discurso de Lula teria sido uma sutil sinalização em favor da "flexibilização" das leis trabalhistas ${ }^{10}$.

Uma vez instalado o Fórum, cada bancada foi instigada a se posicionar. Em comparação com o período anterior, o governo não defendia uma flexibilização sem limites dos direitos trabalhistas, mas também não se opunha totalmente. Contraditoriamente, situou-se entre as referências históricas do seu núcleo petista e sindicalista ${ }^{11}$ e os compromissos estabelecidos com sua base aliada. A aposta no "diálogo social" seria o melhor caminho para a solução dos conflitos e das divergências entre capital e trabalho, mas também para lidar com suas tensões internas.

\footnotetext{
9 Disponível em: <http://bit.ly/2u9MLTa>. Acesso em: 11 jul. 2018.

${ }^{10}$ Cf. pronunciamento do presidente da Associação Nacional dos Magistrados da Justiça do Trabalho, Grijalbo Coutinho, na Folha de São Paulo, 30 jul. 2003.

11 Dos 21 membros da bancada do governo no Fórum, pelo menos sete tinham sido dirigentes ou assessores da CUT, dois dos quais ex-presidentes.
} 
Os empresários, de sua parte, continuavam pressionando pela flexibilização. Mas, ao contrário de antes, buscavam inserir suas demandas na moldura do "diálogo social". Para isso, justificavam-se com o argumento de que os encargos trabalhistas eram elevados e, por isso, favoreciam o desemprego e a informalidade no mercado de trabalho. Para o então presidente da CNI, Armando Monteiro Netto, a "disfuncionalidade" do sistema de relações de trabalho no país resultava das "dificuldades que as empresas têm, ante a rigidez da legislação, de gerar novos empregos e preservar os existentes". Publicamente, defendeu o FNT como a esperança de uma "nova modelagem para as relações de trabalho", com garantia à "negociação voluntária, dentro de um marco regulatório básico, não interventivo”. Contudo, não deixava de mirar na viabilização da flexibilidade:

Uma das vantagens da possibilidade de adaptação da legislação trabalhista à realidade e às necessidades dos parceiros sociais empregadores e trabalhadores está exatamente na sua flexibilidade, não só porque possibilita o permanente e rápido ajuste à dinâmica das mutações socioeconômicas, como também atende às múltiplas peculiaridades e diferenças regionais, setoriais e empresariais do país ${ }^{12}$.

Entre as centrais sindicais, haviam se estabelecido visões divergentes sobre o tema da flexibilização. Quando o governo retirou o Projeto de Lei nº 5.483 do Congresso, a CUT afirmou que não era contra as reformas na CLT, mas que se posicionava "contra a flexibilização de direitos históricos, como $13^{\circ}$ salário, licença maternidade, por exemplo". Enquanto isso, a FS, mesmo a favor do Projeto, não discordava de seu arquivamento desde que houvesse empenho em reformular a legislação trabalhista: "o projeto como está não prejudica

12 Folha de São Paulo, 13 set. 2003. 
nenhum trabalhador". A Social Democracia Sindical (SDS), que também era favorável ao Projeto, argumentava que "o projeto era melhor que nada, mas era insuficiente" ${ }^{13}$.

Segundo Colombi (2018), no Fórum, apesar das diferenças e divergências, houve importantes convergências entre as duas maiores centrais, CUT e FS. Enquanto a FS defendia a unicidade na base e pluralidade na cúpula sindical, o reconhecimento das centrais e a extinção gradativa do imposto sindical (e sua substituição por uma contribuição "retributiva negocial" aprovada em assembleia); a CUT, mesmo com a referência histórica da liberdade e autonomia sindical, se mostrava disposta a negociar a manutenção parcial da estrutura sindical. Sobretudo à CUT se impôs o objetivo de buscar construir consensos, de modo a evitar expor o governo ao desgaste político.

A primeira pauta deliberou se os trabalhos deveriam começar pela discussão da reforma sindical ou da reforma trabalhista. A primeira era defendida pela centrais, 112 enquanto a segunda, mais claramente pela bancada dos empresários. A posição do governo favorável à primeira foi decisiva para que esta prevalecesse.

A discussão sobre a reforma sindical se estendeu até março de 2004 e resultou nos seguintes acordos principais: reconhecimento legal das Centrais Sindicais; instituição do contrato coletivo para todos os ramos da economia; fim do Imposto Sindical; organização sindical por ramo de atividade econômica (e não mais por categoria profissional); fim do monopólio da representação e sua substituição por um sistema de reconhecimento sindical de caráter participativo e plural; relativização do Poder Normativo da Justiça do Trabalho; garantia e ampliação do direito de greve; criação do Conselho Nacional de Relações de Trabalho (CNRT).

Entre as principais divergências, sobressaíram: liberdade e autonomia sindical versus unicidade sindical; grau de

13 Folha de São Paulo, 4 jan. 2003. 
centralização e articulação das negociações coletivas; existência de legislação de sustento para a negociação coletiva; reformulação ou extinção do Poder Normativo da Justiça do Trabalho; reconhecimento e garantias do direito de greve; garantias de organização por local de trabalho.

Apesar dos limites, as centrais sindicais consideraram o resultado favorável. Dali resultou o Projeto de Lei (PL) $\mathrm{n}^{\mathrm{o}} 4.554 / 2004^{14}$ e a PEC n⿳0 369/2005 ${ }^{15}$. Para Denise, ex-diretora da CUT que atuou no Fórum, "a PEG saiu bem mais progressista e favorável a uma visão correspondente ao sindicalismo autônomo e classista do que aos conservadores, desagradando-os e também ao empresariado..." ${ }^{16}$. Por isso, foram fortes as resistências geradas no Congresso, sobretudo por parte dos segmentos empresariais. Luis Marinho, então Ministro do Trabalho e ex-presidente da CUT, chegou a admitir que a bancada empresarial do Congresso ameaçava reter a discussão sobre a reforma sindical porque o governo demorava em encaminhar a reforma trabalhista, e na sequência completou: "É evidente que a reforma sindical tem prevalência na medida em que pode estimular o fortalecimento da negociação, que é o principal pilar para se realizar uma reforma trabalhista ou não"17.

Mas divergências também ficaram evidenciadas do lado dos sindicalistas ${ }^{18}$. A isso se somou o quadro de instabilidade

\footnotetext{
14 "Regulamenta o artigo $8^{\circ}$ da Constituição Federal, que dispõe sobre a organização sindical, e dá outras providências". Disponível em: $\langle$ http://bit.ly/2u7wRsA $>$. Acesso em: 11 jul. 2018.

15 "Institui a contribuição de negociação coletiva, a representação sindical nos locais de trabalho e a negociação coletiva para os servidores da Administração Pública; acaba com a unicidade sindical; incentiva a arbitragem para solução dos conflitos trabalhistas e amplia o alcance da substituição processual, podendo os sindicatos defender em juízo os direitos individuais homogêneos". Disponível em: <http:/ / bit.ly/2NGDwlz>. Acesso em: 11 jul. 2018.

${ }_{16}$ Entrevista concedida aos autores em maio de 2018.

17 Disponível em: <http://bit.ly/2JbXm50>. Acesso em: 11 jul. 2018.

18 No interior da CUT ganhou força uma divergência manifestada sobretudo pela Corrente Sindical Classista, ligada ao PCdoB. Por discordar dos questionamentos
} 
política que se estabeleceu entre 2005 e 2006, com a crise do "mensalão". O projeto não avançou no Congresso e o próprio Fórum se esvaziou, antes que tivesse seguido com a discussão sobre a reforma trabalhista.

O Governo ainda tentou uma "minirreforma", a fim de agilizar a aprovação de medidas contidas no texto do FNT, mas também não obteve sucesso ${ }^{19}$. Restou ao final, em negociações paralelas, o encaminhamento de algumas medidas de forma pontual. Entre elas: a Lei $n^{0}$ 11.648/2008, que reconheceu legalmente as centrais ${ }^{20}$; a Portaria $n^{\circ} 186 / 2008$, detalhando os procedimentos necessários ao registro, impugnação e negociação de eventuais conflitos de representação, o que na prática permitia a pluralidade nas entidades sindicais de grau superior (federações e confederações); a criação do Conselho de Relações de Trabalho (CRT) pela Portaria no 2.092/2010, do Ministério do Trabalho e Emprego.

\section{O CRT como experiência de participação sindical em espaços institucionais}

A primeira vez em que surgiu a ideia de um conselho do trabalho no Brasil (inspirando-se na Convenção 144

\footnotetext{
ao princípio da unicidade sindical, a CSC decidiu, em 2006, sair da CUT para criar a Central Brasileira de Sindicatos (CTB) (Galvão, Marcelino e Trópia, 2015).

19 Ver matéria da Folha Online, disponível em: <http://bit.ly/2L39w1E $>$. Acesso em: 11 jul. 2018.

${ }^{20}$ Enquanto entidades nacionais de representação geral dos trabalhadores, cabia às centrais "coordenar a representação dos trabalhadores por meio das organizações sindicais a ela filiadas" e "participar de negociações em fóruns, colegiados de órgãos públicos e demais espaços de diálogo social que possuam composição tripartite, nos quais estejam em discussão assuntos de interesse geral dos trabalhadores". Para ser beneficiada, a central deverá contar com no mínimo 100 sindicatos distribuídos em 5 regiões do país; em 3 dessas regiões, deverá ter um mínimo de 20 sindicatos em cada uma; ter sindicatos filiados em no mínimo 5 setores de atividade econômica; representando no mínimo $7 \%$ do total de empregados sindicalizados no país. A indicação pela central sindical de re presentantes nos fóruns tripartites, conselhos e colegiados de órgãos públicos deverá seguir a proporcionalidade do índice de representatividade nacional de cada central" Disponível em: $<$ http://bit.ly/2L39Kpw>. Acesso em: 11 jul. 2018.
} 
da OIT $^{21}$ ) foi na gestão de Walter Barelli no Ministério do Trabalho, quando se criou um ambiente propício ao debate sobre regulação pública das relações de trabalho. O Conselho Nacional do Trabalho (CNTb) foi criado pelo Decreto $n^{\circ} 860 / 1993^{22}$. De caráter consultivo, previa uma constituição quadripartite e não paritária. Foram reservados sete lugares para o Governo (Ministério do Trabalho; Secretaria de Planejamento, Orçamento e Coordenação da Presidência da República; Ministério da Agricultura, do Abastecimento e da Reforma Agrária; Ministério da Educação e do Desporto; Ministério da Indústria, do Comércio e do Turismo; Ministério da Ciência e Tecnologia; Ministério do Meio Ambiente), cinco para os empresários (CNA, CNI, Confederação Nacional do Comércio [CNC], Confederação Nacional do Transporte [CNT] e Febraban), cinco para as entidades sindicais (CUT, CGT-Confederação, CGT-Central, FS e Contag) e quatro para a "sociedade civil” (OAB, CNBB, PNBE e Departamento Intersindical de Estatísticas e Estudos Sócio-Econômicos [Dieese]). O CNTb deveria realizar em intervalos de no máximo quatro anos uma Conferência Nacional do Trabalho. A criação do CNTb sugeria um movimento de democratização das relações de trabalho no Brasil. Contudo nunca foi instalado.

Em 1995, no governo FHC, o decreto anterior foi substituído pelo Decreto $\mathrm{n}^{\mathrm{o}}$ 1.617. No novo desenho, o CNTb assumiu um formato tripartite e paritário, tendo reservado seis lugares para cada bancada. O Governo seria representado pelos Ministérios do Trabalho, do Planejamento e Orçamento, da Fazenda, da Previdência e Assistência

\footnotetext{
${ }^{21}$ Esta Convenção foi aprovada em 1976. O texto se refere a "consultas efetivas" de natureza tripartite sobre assuntos da regulação das relações de trabalho. No Brasil, o texto da Convenção 144 foi aprovado pelo Congresso em 1989, ratificado em 1994 e promulgado em 1998. Disponível em: <http://bit.ly/2NJ6ZeQ>. Acesso em: 11 jul. 2018.

${ }^{22}$ Disponível em: <http://bit.ly/2N9XJPY>. Acesso em: 11 jul. 2018.
} 
Social, da Agricultura, do Abastecimento e da Reforma Agrária e da Indústria, Comércio Exterior e Turismo. Deveriam representar os empresários a CNI, CNC, CNA, CNT, Confederação Nacional das Instituições Financeiras (CNIF) e Câmara Brasileira da Indústria da Construção (CBIC). Quanto aos trabalhadores, se fariam representar pela CUT, CGT-Confederação e FS. Também nessa versão, o Conselho jamais foi instalado. Conforme vimos, as medidas governamentais de então (em muito orientadas à desregulamentação das relações de trabalho) foram tomadas sem que tivesse sido acionado o CNTb nem qualquer outro espaço tripartite de consulta.

Com o FNT, em 2003, o tema volta à baila, sendo contemplado no texto da reforma sindical. O PL que daí derivou, ao não prosperar no Congresso, levou junto a proposta de um Conselho Nacional de Relações de Trabalho (CNRT). O governo ainda tentou por Medida Provisória 116 (MP), de $n^{\circ}$ 294/06 ${ }^{23}$, inseri-lo na estrutura do Ministério do Trabalho, mas foi rejeitada, junto com a MP $\mathrm{n}^{\circ} 293$ que previa o reconhecimento legal das centrais sindicais ${ }^{24}$. No entanto, ambas as propostas foram retomadas mais à frente. $\mathrm{O}$ reconhecimento das centrais se fez pela Lei nº 11.648/2008 e a criação do Conselho de Relações de Trabalho (CRT), por Portaria do Ministério do Trabalho e Emprego (MTE), de no 2.092/2010²5.

A criação do CRT só se efetivou no segundo mandato de Lula, em 2010. No vácuo que se estabeleceu com o esvaziamento e desativação do FNT, a CUT buscou ampliar sua atuação no Congresso, visando sobretudo barrar iniciativas que ameaçavam prejudicar os trabalhadores, como o debate sobre terceirização. Nas palavras de Denise,

\footnotetext{
${ }^{23}$ Ver <http://bit.ly/2NJ8U32>. Acesso EM: 11 jul. 2018.

${ }^{24}$ Ver Folha Online, disponível em: <http://bit.ly/2KMOyIv $>$. Acesso em: 11 jul. 2018.

${ }^{25}$ Disponível em: <http://bit.ly/2mamEHD>. Acesso em: 11 jul. 2018.
} 
Se a PEC nº 369/2005 avançasse seria necessário ter um espaço de diálogo tripartite para tentar realizar os ajustes, adequações e inclusive um posicionamento do CRT diante dos questionamentos do parlamento em relação ao conteúdo dela durante a tramitação (para que empregadores, governo e trabalhadores não fossem cada um com um posicionamento pressionar o parlamento e houvesse uma tentativa de se chegar em algum ponto comum) [...] Por que o CRT poderia então tentar negociar ou resolver pontos da Reforma Sindical importantes, vamos assim dizer no "varejo" já que a grande reforma ampla, geral e integral, como previa a PEC nํㅜ 369, não andou. A ideia era selecionar pontos, tais como financiamento sindical, OLT, negociação coletiva e tentar "renegociar" e encaminhar um a um no CRT ${ }^{26}$.

Nesse esforço, ganhou maior relevância a construção de uma agenda convergente com as demais centrais. Era sabido que enquanto a CUT tinha melhor trânsito junto ao Palácio, a FS tinha mais influência nas articulações no Parlamento (Colombi, 2018).

Em 2010, antes das eleições, foi realizada uma nova Conferência Nacional da Classe Trabalhadora (Conclat) ${ }^{27}$ (Ramalho, Cordeiro e Silva, 2014). Sua convocação foi feita pela CTB, CUT, FS, União Geral dos Trabalhadores (UGT), Nova Central Sindical dos Trabalhadores (NCST) e Central Geral dos Trabalhadores do Brasil (CGTB) ${ }^{28}$. Seu propósito era ajustar a agenda e buscar influir nas eleições.

Desde o início do segundo mandato de Lula, em 2007, o MTE havia saído do comando do PT e passado ao do PDT, com Carlos Lupi como titular. Nessa ocasião, a FS ganhou

\footnotetext{
${ }^{26}$ Entrevista dada aos autores em maio de 2018.

27 A primeira, histórica, reunindo todas as correntes do movimento sindical brasileiro, havia sido realizada em 1981.

28 Nesse momento, existiam outras centrais: CSP-Conlutas, com hegemonia do PSTU e a Intersindical, vinculada ao PSOL.
} 
mais espaço no MTE, dividindo-o com a CUT. Lupi não gozava do poder de influência estratégica no governo. Com isso, o MTE não conseguiu articular um espaço tripartite que estivesse à altura da importância do FNT para o governo. As principais decisões governamentais com implicações para os trabalhadores foram tomadas, nesse período, em negociações diretas entre representantes empresariais e/ou sindicais junto ao Palácio ${ }^{29}$. Mesmo assim, as negociações para a definição do formato do Conselho foram intensas e contaram com a participação direta das principais representações dos trabalhadores, dos empresários e do MTE.

A Portaria no 2.092/10 atribuiu ao CRT um caráter consultivo, tripartite e paritário. Mas, diferentemente das versões anteriores, sendo instituído por Portaria do MTE, a este viu circunscrito, não contando com a participação de outros ministérios. "Esse é um ponto de fraqueza desse Conselho", asseverou Manoel Messias ${ }^{30}$, ex-dirigente da CUT que se 118 tornou Secretário de Relações de Trabalho do MTE e que, nessa função, coordenou o CRT entre 2012 e 2016.

Para se garantir paridade em relação à representação de empregadores, na definição dos representantes dos trabalhadores foi considerado o critério de proporcionalidade previsto na Lei $n^{0} 11.648 / 2008$. Foram previstas ainda três câmaras bipartites, formadas entre o MTE e as bancadas dos trabalhadores, dos empregadores e dos servidores públicos.

\footnotetext{
29 Uma situação com flagrante relutância no acionamento, pelo governo, de consultas tripartites em casos de importância para os trabalhadores ocorreu na discussão sobre a desoneração de folhas de pagamento, ocorrida em 2011, que redundou na Lei $\mathrm{n}^{\mathrm{o}}$ 12.546/2011. Apesar de envolver 56 setores de atividade, afetando o Programa de Integração Social do Programa de Formação do Patrimônio do Servidor Público (PIS/Pasep) e a Previdência Social e, em consequência, ter implicações importantes para os recursos do FAT, até mesmo o Codefat não chegou a ser consultado (Ramalho, Cordeiro e Silva, 2014). Segundo apuração da Folha, a decisão de fazer a reunião buscou reduzir as críticas de centrais sindicais, que reclamaram de não terem sido consultadas sobre as mudanças que tornaram mais rigorosas as regras de concessão de benefícios como seguro-desemprego, abono salarial e pensão pós-morte.

${ }^{30}$ Entrevista concedida aos autores em maio de 2018.
} 
Embora criado em 2010, o Conselho só foi instalado em 2011, na gestão de Brizola Neto (Portaria $n^{\circ} 754$ ). O primeiro ano foi destinado aos entendimentos sobre o regimento interno e à instalação das câmaras bipartites (Colombi, 2018). Na opinião de Messias ${ }^{31}$, Brizola Neto tinha menor peso político e compromisso com o Conselho mas, paradoxalmente, foi quando este começou a funcionar.

O registro sindical foi o primeiro tema em discussão no CRT. As denúncias sobre cobrança de propina no Ministério para liberar o registro de sindicatos provavelmente foi uma das causas da saída de Lupi ${ }^{32}$. O debate visou redefinir as regras do registro e implicou em um esforço de construção de uma tabela de categorias, tendo como base a Classificação Nacional de Atividades Econômicas (CNAE). Conforme testemunhou Messias $^{33}$, houve forte envolvimento das bancadas de trabalhadores e de empregadores nesse debate. A negociação fluiu bem, inclusive porque foi conduzida por representantes sindicais e empresariais que haviam participado, com êxito, de uma negociação em 2007 sobre o Fator Acidentário de Prevenção (FAP), no âmbito do Fórum Nacional da Previdência. Sobre as novas regras para o registro sindical, a negociação foi bem-sucedida, chegando-se ao final a um acordo.

Outros pontos foram pautados (seja pelo MTE, seja por alguma das demais bancadas), especialmente os que se encontravam acumulados na Secretaria de Relações do Trabalho (SRT), na maioria dos casos se tratando de temas pontuais. Foram exemplo o ponto eletrônico (sobre o qual não houve acordo), a regulamentação do trabalho de demonstradores de supermercados (também sem resultar em acordo), um projeto de lei sobre práticas antissindicais (que encontrou resistência por parte da bancada

\footnotetext{
${ }^{31}$ Entrevista concedida aos autores em maio de 2018.

32 Cf. matéria do G1 disponível em: <https://glo.bo/2L3qksB >. Acesso em: 11 jul. 2018.

33 Entrevista concedida aos autores em maio de 2018
} 
empresarial, não havendo acordo), o registro de músicos e de outras categorias profissionais, entre outros. Apesar de seu caráter secundário, conforme observou Messias ${ }^{34}$, o debate que se processou em torno desses assuntos foi importante para se criar um ambiente de negociação. $\mathrm{O}$ problema foi o MTE e o CRT não conseguirem trazer para o seu âmbito a discussão e o encaminhamento dos temas mais importantes da agenda do governo referidas às áreas de trabalho, emprego e renda. Outros espaços de negociação criados e mantidos entre os dois mandatos de Lula, como o CDES, haviam perdido o dinamismo anterior. As bancadas de empresários e de trabalhadores reclamavam desse fato, e cada uma buscava tratá-lo diretamente com o Planalto. Algumas delas foram encaminhadas em conversas tripartites, embora por formações $a d$ hoc, não passando por dentro do Conselho e sem o protagonismo do MTE. Note-se que com menos de um ano o MTE muda de mãos novamente, 120 quando assume Manoel Dias, também do PDT (aliado de Lupi). A mudança, contudo, afeta pouco o funcionamento do CRT. O próprio Manoel Messias seguiu titular da SRT.

O debate sobre o tema da terceirização foi emblemático das limitações do Conselho. Mesmo tendo sido provocado pela bancada empresarial, esse tema jamais foi debatido no CRT. O assunto foi, ao contrário, tratado em um espaço criado especificamente para isso, a Mesa Quadripartite, envolvendo representantes do governo, das centrais sindicais, dos empresários e do Congresso Nacional. Mesmo envolvendo basicamente os mesmos atores do CRT, este não conseguiu se afirmar como espaço de negociação sobre o tema. Desde a apresentação do PL n⿳0 4.330/2004 pelo deputado Sandro Mabel (então no Partido Liberal), praticamente liberando a terceirização sem restrições, as centrais sindicais, com destaque para a CUT, buscaram tomar iniciativas em contrário.

${ }^{34}$ Entrevista concedida aos autores em maio de 2018. 
Entre elas, colaborou com a formulação do PL nº 1.621, apresentado em 2007 pelo deputado federal Vicente Paulo da Silva (PT), que basicamente propunha a proibição da terceirização em atividade fim; a igualdade de direitos entre terceirizados e trabalhadores diretos; e a responsabilidade solidária do contratante (Dau, 2009). Em 2009, a CUT conduziu a Campanha Nacional de Combate à Terceirização, Precarizar Não! (Colombi, 2018). Em 2013, as centrais se articularam para cobrar do governo a constituição da Mesa Quadripartite. Em sua implementação, a bancada do governo se reuniu previamente com vários ministérios (Trabalho, Fazenda, Planejamento, Indústria e Comércio, Banco Central e outros órgãos). O processo que se seguiu foi muito intenso, tendo avançado na construção de entendimentos (conforme atestou Messias ${ }^{35}$ ), mas se frustrou ao final, não consumando o acordo. Enquanto os empresários não aceitavam discutir o tema da representação sindical dos terceirizados na mesma categoria econômica da empresa contratante, os trabalhadores não aceitavam que não houvesse tratamento distinto para a terceirização de atividades meio e fim ${ }^{36}$.

Ao contrário, o debate sobre o contrato de curta duração foi negociado no CRT. Ganhara relevância na agenda das centrais a negociação de Compromissos nacionais, estabelecidos em regime tripartite, referidos a setores específicos. Alguns dos mais relevantes foram o Compromisso nacional para aperfeiçoar as condições de trabalho na cana de açúcar, negociado em 2009, o Compromisso nacional para aperfeiçoar as condições de trabalho na indústria da construção, firmado em 2012, após dois anos seguidos de greves nacionais nas obras do Programa de Aceleração do Crescimento (PAC)

\footnotetext{
35 Entrevista concedida aos autores em maio de 2018.

$36 \mathrm{Na}$ avaliação de Messias (entrevista concedida aos autores em maio de 2018), mais uma vez as centrais não atuaram com posições comuns. O tema sobretudo dividiu a CUT, CTB e Intersindical, de um lado, e a FS e UGT, de outro. De outra parte, a CUT se via fragilizada pelas divergências internas.
} 
(Oliveira, 2014), e o Compromisso nacional para aperfeiçoar as condições de trabalho na Copa do Mundo da FIFA, realizado em 2014. No final de 2013, a bancada dos empregadores e representantes do MTE pautaram no CRT a necessidade de regulamentação dos contratos de curta duração, o que, segundo Ramalho, Cordeiro e Silva (2014), teria gerado grande tensão. Os empregadores reclamavam da necessidade de maior segurança jurídica na contratação por prazo de curtíssima duração, sem o ônus tributário que incide em um vínculo formal de emprego, sobretudo com foco no setor de hotéis, bares e restaurantes no período da Copa do Mundo. A resistência das centrais, em sua maioria, impediu o acordo. Um conselheiro da CGTB vaticinou: "na Copa veio a ideia de criar uma nova legislação de contrato de trabalho, em que você não teria mais os direitos da CLT, e se isso vira lei..." (Ramalho, Cordeiro e Silva, 2014, p. 50). Para Messias ${ }^{37}$, havia diferenças entre e dentro das banca122 das. A posição dos empresários implicava em flexibilizar para além do que o MTE estava disposto a ceder. Entre os sindicalistas não houve consenso.

$\mathrm{Na}$ mesma direção, foi encaminhado o tema do Programa de Proteção ao Emprego, embora neste caso tenha sido produzido um acordo, mas que não envolveu centralmente o espaço do CRT. A proposta começou a ser discutida em fins de $2014^{38}$, mas só em 2015, com o agravamento da crise, é que o governo puxou o debate com centrais sindicais e empregadores, com as negociações sendo conduzidas de forma tripartite diretamente pelo Palácio, embora para isso tenha se utilizado do espaço de negociação mantido pelo CRT, conforme observou Messias ${ }^{39}$. A proposta se concretizou na MP nº 680/2015, que se converteu

\footnotetext{
37 Entrevista concedida aos autores em maio de 2018.

38 Ver matéria da Folha Online, disponível em: <http://bit.ly/2maXCIs $>$. Acesso em: 11 jul. 2018.
}

39 Entrevista concedida aos autores em maio de 2018. 
na Lei $\mathrm{n}^{\mathrm{o}} 13.189$, de $2015^{40}$, consistindo em promover uma redução na jornada de trabalho (em até $30 \%$ ) acompanhada da redução de salário (de no máximo 15\%). Tal medida deveria valer para alguns setores dentre os mais afetados pela crise, por um período determinado (vigência até final de 2016), ainda cabendo ao Governo uma complementação de parte do salário dos trabalhadores assistidos (limitada a $65 \%$ do maior benefício do seguro-desemprego) e isenções de impostos ${ }^{41}$.

A discussão sobre nova regulamentação do trabalho aos domingos e feriados, ao contrário, foi pautada no CRT e ao final se chegou a um consenso materializado na Portaria $n^{\circ} 945 / 2015$. Ainda no governo FHC, com a Lei $\mathrm{n}^{\mathrm{o}}$ 10.101/2000, o trabalho aos domingos e feriados foi regulamentado, sob protesto da CUT, admitindo-se como única restrição a permissão de trabalho em apenas um domingo por mês (Colombi, 2018). Em 2007, com a Lei nº 11.603, havia sido ratificado o trabalho aos domingos para os comerciários, sendo permitido no máximo dois domingos ao mês, mas nesses casos e nos feriados era necessária a aprovação em convenção coletiva e atenção à legislação municipal. Quanto à Portaria n ${ }^{0}$ 945/2015, esta reafirmou a necessidade de acordo coletivo específico firmado entre empregadores e entidade representativa da categoria profissional de empregados. Outras condicionalidades foram também previstas, especialmente quanto ao acordo coletivo específico: prever escala de revezamento, prazo de vigência da prestação do trabalho, condições específicas de segurança e saúde para o trabalho em atividades perigosas e insalubres etc. Segundo Messias ${ }^{42}$, teria ocorrido um longo processo de

\footnotetext{
40 Disponível em: <http://bit.ly/2maXCIs>. Acesso em: 11 jul. 2018.

${ }^{41}$ Ver a Lei n⿳o $13.189 / 2015$ na nota anterior e a matéria da Folha Online disponível em: <http://bit.ly/2ztfmbj>. Acesso em: 11 jul. 2018.

${ }^{42}$ Entrevista concedida aos autores em maio de 2018.
} 
negociação, um exercício de tripartismo: "foi difícil, longo, mas que se chega ao outro lado".

Outros temas relevantes para os trabalhadores foram tratados com completo alheamento do CRT. A condução das negociações sobre Plano Brasil Maior (que determinou a política industrial, tecnológica, de serviços e de comércio exterior para o período de 2011 a 2014) envolveu vários ministérios e foi conduzido pela Agência Brasileira de Desenvolvimento Industrial (ABDI), ligada ao Ministério da Indústria, Comércio Exterior e Serviços (MDIC). Em setembro de 2015, o governo resolve criar o Fórum de Debates sobre Políticas de Emprego, Trabalho e Renda e Previdência Social, envolvendo representantes dos trabalhadores, empresários, aposentados e pensionistas ${ }^{43}$, sob a coordenação dos Ministérios do Planejamento, Fazenda, Previdência e Trabalho, desconhecendo completamente o papel do CRT. Já ao final do governo Dilma, a distância entre este e as 124 centrais sindicais se agravou. Em 2015, foi bastante criticado pelas centrais o fato de não terem sido consultadas sobre as mudanças nas regras de concessão de benefícios nos casos do seguro-desemprego, do abono salarial e da pensão pós-morte, tornando tais regras mais rigorosas ${ }^{44}$.

O Pleno Tripartite do CRT, embora tenha funcionado, o fez sob limites. Quanto às Câmaras bipartites, estabeleceram-se com menos consistência. Dentre essas, apenas a de Governo e Trabalhadores teve um funcionamento mais regular, com o foco recaindo sobre aferição da representatividade das centrais, questões envolvendo disputas sindicais, definição de critérios para redefinir a representação dos trabalhadores da agricultura familiar e dos assalariados, projeto de lei sobre práticas antissindicais, entre outros. Em poucas ocasiões, foram tratados temas de cunho trabalhista, a exemplo do trabalho de curta duração

\footnotetext{
${ }^{43}$ Ver matéria disponível em: <http://bit.ly/2md0cNY>. Acesso em: 11 jul. 2018.

${ }^{44}$ Ver matéria da Folha Online disponível em: <http://bit.ly/2L0A9Ym>. Acesso em: 11 jul. 2018.
} 
e do trabalho aos domingos e feriados. Eventualmente as atas explicitam divergências nos posicionamentos das centrais.

A Câmara entre Governo e Servidores Públicos foi instalada em dezembro de 2011. Seu funcionamento foi bastante irregular, tendo muito poucas reuniões realizadas. A hipótese é a de que esta Câmara ficou paralisada devido a um impasse na regulamentação da Convenção 151, da OIT, que trata do direito de negociação no serviço público, ratificada no final do governo Lula e desde então pendente de um arcabouço jurídico na legislação nacional.

A Câmara entre Governo e Empresários foi instalada em outubro de 2011, não tendo se reunido novamente por mais de dois anos. A partir de então ela seguiu com reuniões esporádicas. Entre outros pontos, foram discutidos o contrato de curta duração e a representação da organização sindical de setores patronais. Parece claro nas atas que o interesse maior dessa Câmara foi sempre o da temática trabalhista, na busca de segurança jurídica no exercício de formas diversas de contrato flexível.

Nos últimos instantes do governo Dilma, em abril de 2016, a presidenta revogou o Decreto $\mathrm{n}^{\circ}$ 1.617, de 1995, e instituiu, com o Decreto $\mathrm{n}^{\mathrm{o}}$ 8.732, o Conselho Nacional do Trabalho como órgão do Ministério do Trabalho e Previdência Social. Confirma-se seu caráter consultivo, tripartite e paritário e se reafirma o propósito de "promover o primado da justiça social e o tripartismo no âmbito da legislação trabalhista, com vistas à democratização das relações de trabalho". Para a definição das representações das bancadas, seguiu-se basicamente os mesmos critérios da Portaria de $2010^{45}$.

Para Messias ${ }^{46}$, é evidente que o governo, nesse processo, não fez uma aposta no tripartismo, perseguindo uma efetiva participação dos três segmentos na determinação das

\footnotetext{
45 Disponível em: <https://bit.ly/2OD4hI2>. Acesso em: 11 jul. 2018.

46 Entrevista concedida aos autores em maio de 2018.
} 
políticas com incidência no tema do trabalho. As situações criadas nessa direção foram quase sempre produto de iniciativas de governantes e representantes de trabalhadores e, em menor medida, de empresários. De fato, um dos limitadores do exercício do tripartismo é o desinteresse do segmento empresarial, apesar de se poder ver alguma retórica nesse sentido. A representação sindical ousou pouco em matéria de regulação das relações de trabalho; conteve-se em uma atitude fundamentalmente reativa às pressões empresariais e ou governamentais.

O CRT se mostrou muito restrito e limitado em seu escopo, sua pauta e seus resultados. Por tudo isso, durante todo o período coberto por esta pesquisa, ele se mostrou incapaz de se converter em lugar, por excelência, de discussões sobre os temas da regulação do trabalho no país. Na percepção de Colombi (2018), o CRT, ao fim e ao cabo, se configurou como um espaço para o movimento sindical buscar garantir sua própria sobrevivência, enquanto que para o setor patronal funcionou como meio de se certificar que medidas contrárias a seus interesses não seriam aprovadas.

Em 2015, ano em que se aprofunda a crise econômica e política e crescem as manifestações pelo impeachment de Dilma, as atas do Pleno Tripartite do CRT e das Câmaras Bipartite registram reuniões até maio. Entre abril e agosto, apesar de ter caráter provisório, o novo governo deu início ao desmanche do legado social dos governos Lula/Dilma.

\section{Considerações finais}

Desde a eclosão das lutas operárias e populares nos anos 1970, muito se percorreu entre formas de ação sindical direta e de participação institucional, com tensões internas e disputas para fora, com os campos empresarial e governamental. Nessa trajetória, o sindicalismo se modificou e ajudou a constituir e transformar os espaços nos quais atuou. 
Na década de 1980, entre uma e outra forma de ação, registraram-se conquistas inéditas, sobretudo consagradas na Constituição de 1988. No período seguinte, um quadro socioeconômico adverso e governos hostis levaram a um arrefecimento das mobilizações sindicais e a uma certa prioridade (em parte por compensação) à participação em fóruns, comissões, conselhos e outros tipos de espaços de negociação social e de gestão de políticas públicas. Isso ocorreu, muitas vezes, ao preço alto desse tipo de ação sindical se restringir ao trato de políticas sociais focais e compensatórias e se ver preso a compromissos inibidores. A partir de 2003, um ambiente socioeconômico e político-institucional mais favorável abriu novas possibilidades, estimulando ainda mais a participação sindical institucional. O CDES, o FNT e o CRT foram alguns dentre os mais relevantes espaços de formulação concertada de políticas econômicas, sociais e laborais.

A experiência sindical vivenciada nas últimas décadas se revelou complexa e desafiadora. Neste estudo, procuramos combinar uma reconstituição histórica ampla - para uma melhor apreensão dos nexos entre o que aqui tomamos como pontos de partida e de chegada - e uma abordagem focada na experiência do CRT.

Um tema sobressaiu: o das possibilidades e limites da participação sindical institucional. Contextos diferenciados testaram caminhos e estratégias diversos. Não há lições definitivas. Alguns aspectos, entretanto, podemos realçar.

Os espaços de participação institucional se mostraram, apesar dos avanços, muito frágeis. Mesmo nos governos Lula-Dilma, em que os espaços de negociação social se multiplicaram, muitas vezes não passaram de formações $a d$ hoc (como a Mesa Quadripartite para tratar da regulação da terceirização).

A negociação tripartite, inspirada no modelo da OIT, esbarra, no caso brasileiro, em pelo menos três obstáculos: os empresários não têm nessa negociação uma prioridade, 
dela participando só quando a situação o exige ou quando têm necessidade desse espaço para obter legitimação social de suas demandas; os governos refletem a pouca referência da sociedade sobre práticas de participação e experiência no tripartismo; o sindicalismo, embora tenha convergido para atribuir estratégica importância à participação institucional e ao tripartismo, se encontra fortemente marcado por um desenho organizacional fragmentado e uma configuração político-ideológica muito heterogênea e marcada por disputas. Por outro lado, é necessário reconhecer que o exercício da negociação social em espaços tripartite em vários momentos decisivos forçou uma agenda em comum entre as centrais sindicais.

Apesar do sindicalismo ter, de modo geral, se gabaritado ao longo dos anos para ocupar uma grande diversidade de espaços institucionais, sua ação neles têm a marca da reatividade, agindo sobretudo quando se vê ameaçado pela ação governamental e/ou empresarial. Foi assim nos anos 1990, mas também sob os governos Lula-Dilma, quando as possibilidades se ampliaram.

Apesar das distâncias que hoje se nota entre as bandeiras que marcaram o surgimento do "novo sindicalismo" e as propostas defendidas pelas representações sindicais nos espaços institucionais (a exemplo do tema da liberdade e autonomia sindical e sobre como se fez concessões a ele por ocasião da discussão no FNT), é possível se constatar nexos entre um e outro.

A ruptura que se estabeleceu com o impeachment de Dilma certamente está propiciando ao sindicalismo uma situação desafiadora. Principalmente, ela problematiza uma dinâmica na qual o sindicalismo se encontrava acostumado à ação institucional, enquanto se vê desafiado a retomar com mais centralidade formas (renovadas) de ação direta.

Para ser bem-sucedido, o sindicalismo precisará saber (re)conhecer os novos conflitos do local de trabalho e o 
novo perfil dos trabalhadores. Como construir espaços de participação institucional e negociação social efetivos, do ponto de vista dos trabalhadores e do sindicalismo, em tempo de pressão sistemática por flexibilização e perda de direitos? Não se trata de tarefa simples, com um mundo do trabalho cada vez mais marcado pela informalidade e flexibilização de relações de trabalho em ambientes home office, coworking, virtual, heterogêneo, fragmentado...

\section{Roberto Véras de Oliveira}

é doutor em Sociologia pela Universidade de São Paulo (USP), professor do Departamento de Ciências Sociais e do Programa de Pós-Graduação em Sociologia da Universidade Federal da Paraíba (UFPB), professor do Programa de Pós-Graduação em Ciências Sociais da Universidade Federal de Campina Grande (UFCG) e bolsista de produtividade do CNPq.

\section{Mario Henrique Guedes Ladosky}

é doutor em Sociologia pela Universidade de São Paulo (USP) e professor da Unidade Acadêmica de Ciências Sociais e do programa de Pós-Graduação em Ciências Sociais da Universidade Federal de Campina Grande (UFCG).

\section{Bibliografia}

ABRAMO, Laís Wendel. 1999. O resgate da dignidade: greve metalúrgica e subjetividade operária. Campinas: Editora Unicamp; São Paulo: Imprensa Oficial.

ANTUNES, Ricardo. 1988. A rebeldia do trabalho: o confronto operário no ABC paulista: as greves de 1978-80. Campinas: Editora Unicamp; São Paulo: Ensaio.

ARBIX, Glauco. 1996. Uma aposta no futuro: os primeiros anos da Câmara Setorial da Indústria Automobilística. São Paulo: Scritta.

BALTAR, Paulo Eduardo de Andrade; KREIN, José Dari. 2013. A retomada do desenvolvimento e a regulação do mercado do trabalho no Brasil. Caderno CRH, v. 26, n. 68, pp. 273-292.

BOITO JÚNIOR, Armando (org.). 1991. O sindicalismo brasileiro nos anos 80. São Paulo: Paz e Terra. 
COLOMBI, Ana Paula Fregnani. 2018. A institucionalização do consenso: atuação da CUT e da FS durante os governos do PT (2003-2014). Tese de Doutorado em Economia Aplicada. Campinas: Unicamp.

COMIN, Álvaro Augusto. 1995. A estrutura sindical corporativa: um obstáculo à consolidação das Centrais Sindicais no Brasil. Dissertação de Mestrado em Sociologia. São Paulo: USP.

CENTRAL ÚNICA DOS TRABALHADORES. 1995. Sistema democrático de relações de trabalho: desatar os nós. InformaCUT, n. 250. Não paginado.

DAU, Denise. 2009. A expansão da terceirização no Brasil e a estratégia da CUT de enfrentamento à precarização do trabalho. In: DAU, Denise; RODRIGUES, Iram; CONCEIÇÃO, Jefferson (orgs.). Terceirização no Brasil: do discurso da inovação à precarização do trabalho. São Paulo: Annablume; CUT, pp. 167-186.

GALVÃO, Andréia; MARCELINO, Paula; TRÓPIA, Patrícia Vieira. 2015. As Bases Sociais Das Novas Centrais Sindicais Brasileiras. Curitiba: Appris. GALVÃO, Andréia; TRÓPIA, Patrícia Vieira. 2014. A CSP-Conlutas em perspectiva. In: OLIVEIRA, Roberto Verás; BRIDI, Maria Aparecida; FERRAZ, Marcos (orgs.). O sindicalismo na era Lula: paradoxos, perspectivas e olhares. Belo Horizonte: Fino Traço, pp. 115-148.

HUMPHREY, John. 1982. Fazendo o "milagre": controle capitalista e luta operária na indústria automobilística brasileira. Petrópolis: Vozes; São Paulo: Cebrap.

KREIN, José Dari. 2007. Tendências recentes nas relações de emprego no Brasil: 1990-2005. Tese de Doutorado em Economia Aplicada. Campinas: Unicamp.

KREIN, José Dari; BIAVASCHI, Magda de Barros. 2015. Brasil: os movimentos contraditórios da regulação do trabalho dos anos 2000. Cuadernos del Cendes, v. 32, n. 89, pp. 47-82.

LADOSKY, Mário. 2009. A CUT no Governo Lula: da defesa da liberdade e autonomia à reforma sindical inconclusa. Tese de Doutorado em Sociologia. São Paulo: USP.

MARONI, Amnéris. 1982. A estratégia da recusa: análise das greves de maio/78. São Paulo: Brasiliense.

OLIVEIRA, Francisco. 1998. Corporativismo: conceito ou emplastro? Democracia Viva, n. 3, pp. 7-16.

OLIVEIRA, Marco Antonio. 2002. Política trabalhista e relações de trabalho no Brasil: da era Vargas ao governo FHC. Tese de Doutorado em Ciências Econômicas. Campinas: Unicamp. 
OLIVEIRA, Roberto Véras. 2006. Qualificar para quêe? qualificação para quem? do global ao local: o que se espera da qualificação profissional hoje. São Paulo: UniTrabalho; Campina Grande: EdUFCG. 2011. Sindicalismo e democracia no Brasil: do novo sindicalismo ao sindicato cidadão. São Paulo: Annablume.

2014. Brasil em obras, peões em luta, sindicatos surpreendidos. Revista Crítica de Ciências Sociais, n. 103, pp. 111-136.

POCHMANN, Marcio. 1999. O trabalho sob fogo cruzado: exclusão, desemprego e precarização no final do século, São Paulo: Contexto. 2009. O trabalho na crise econômica no Brasil: primeiros sinais. Estudos Avançados, v. 23, n. 66, pp. 41-52.

RAMALHO, José Ricardo; CORDEIRO, Marina de Carvalho; SILVA, Eduardo Ângelo. 2014. O movimento sindical urbano no exercício da participação. In: LEITE LOPES, José Sérgio; HEREDIA, Beatriz Maria Alasia (orgs.). Movimentos sociais e esfera pública: o mundo da participação: burocracias, confrontos, aprendizados inesperados. Rio de Janeiro: CBAE, pp. 41-65.

RODRIGUES, Iram Jácome. 2011. Sindicalismo e política: a trajetória da CUT (1983-1993). 2. ed. São Paulo: LTr.

RODRIGUES, Leôncio Martins; CARDOSO, Adalberto Moreira. 1993. A Força Sindical: uma análise sócio-política. São Paulo: Paz e Terra.

SADER, Éder. 1988. Quando novos personagens entraram em cena: experiências, falas e lutas dos trabalhadores da Grande São Paulo (1970-1980). Rio de Janeiro: Paz e Terra.

TATAGIBA, Luciana. 2002. Os conselhos gestores e a democratização das políticas públicas no Brasil. In: DAGNINO, Evelina (Org.). Sociedade civil e espaços públicos no Brasil. São Paulo: Paz e Terra, pp. 47-103.

TELLES, Vera da Silva. 1999. Direitos sociais: afinal do que se trata? Belo Horizonte: Editora UFMG.

TRÓPIA, Patrícia Vieira. 2009. Força Sindical: política e ideologia no sindicalismo brasileiro. São Paulo: Expressão Popular. 


\section{DAS GREVES DO ABC AO CONSELHO DE RELAÇÕES DE TRABALHO: CHANCES E LIMITES DA AÇÃO SINDICAL INSTITUCIONAL}

\section{ROBERTO VÉRAS DE OLIVEIRA}

\section{MARIO HENRIQUE GUEDES LADOSKY}

Resumo: Este artigo tem como propósito reconstituir os nexos entre o sindicalismo oriundo das greves operárias e populares desencadeadas a partir de fins da década de 1970 e as condições recentes de regulação do trabalho no Brasil, com particular foco na atuação sindical no Conselho de Relações de Trabalho (CRT), criado em 2010. Não se trata de realizar um balanço dos últimos 40 anos, seja da trajetória do sindicalismo brasileiro, seja dos caminhos da regulação do trabalho no país. Tão somente percorremos em grandes linhas a trajetória sindical desde então, até nos determos no CRT, em sua formatação e agenda, para assim analisar as chances e limites propiciados à atuação sindical. Para tanto, dialogamos com a bibliografia referida ao tema e com pesquisas e reflexões acumuladas pelos autores, assim como apoiamo-nos em pesquisa documental (atas do CRT, leis, decretos, medidas provisórias e portarias), em pesquisa midiática e em entrevistas com membros das bancadas sindical e governista do CRT.

Palavras-chave: Sindicalismo; Ação Institucional; Tripartismo; Regulação das Relações de Trabalho; Brasil.

\section{FROM THE ABC STRIKES TO THE LABOR RELATIONS BOARD: CHANCES AND LIMITS OF INSTITUTIONAL UNION ACTION}

Abstract: The purpose of this article is to reconstitute the links between trade unionism stemming from the workers' and popular strikes that began in the late 1970s and the recent conditions of labor regulation in Brazil, with a particular focus on trade union 
activity in the Labor Relations Council (CRT), created in 2010. It is not a question of carrying out a balance of the last 40 years, either in the trajectory of Brazilian trade unionism or in the ways of regulating labor in the country. We have only followed the trade union trajectory since then, until we stop at the CRT, in its format and agenda, in order to analyze the possibilities and limits of trade union activity. In order to do so, we dialogue with the bibliography on the subject and with research and reflections accumulated by the authors, as well as supporting documentary research (CRT minutes, decrees, provisional measures and ordinances), media research and interviews with union and governor of the CRT.

Keywords: Trade Unionism; Institutional Action; Tripartism; Regulation of Labor Relations; Brazil.

Recebido: 08/06/2018Ａprovado: 26/07/2018 